\title{
The expression pattern of dormancy-associated genes in multiple life-history stages in the rotifer Brachionus plicatilis
}

\author{
N. Y. Denekamp $\cdot$ R. Reinhardt \\ M. W. Albrecht • M. Drungowski - M. Kube • \\ E. Lubzens
}

Published online: 5 November 2010

(C) Springer Science+Business Media B.V. 2010

\begin{abstract}
Rotifer resting eggs retain their viability for several decades in a non-desiccated form and are of interest in discerning the processes associated with dormancy, since in most organisms this phenomenon is linked with desiccation. The expression pattern of candidate genes with biological functions associated with dormancy in several other organisms was examined in rotifers. High-throughput transcriptome profiling revealed three patterns of gene expression in resting eggs: (1) relatively highly expressed genes coding for LEA proteins and putative paralogs of the small heat shock protein family (shsp); (2) genes coding for ferritin (ferr), glutathione-6-transferase ( $g t s$ ) and HSP70, where some of the putative gene
\end{abstract}

Electronic supplementary material The online version of this article (doi:10.1007/s10750-010-0518-y) contains supplementary material, which is available to authorized users.

Guest editors: N. Walz, R. Adrian, J.J. Gilbert, M.T. Monaghan, G. Weithoff \& H. Zimmermann-Timm / Rotifera XII: New aspects in rotifer evolution, genetics, reproduction, ecology and biogeography

N. Y. Denekamp · E. Lubzens $(\square)$

Israel Oceanographic and Limnological Research,

P. O. Box 8030, Haifa 31080, Israel

e-mail: esther@ocean.org.il; elubzens@hotmail.com

R. Reinhardt · M. W. Albrecht · M. Drungowski ·

M. Kube

Max Planck Institute for Molecular Genetics,

Berlin-Dahlem, Germany paralogs of these families show relatively high expression levels and other putative paralogs show relatively low expression levels in resting eggs; and (3) genes with relatively low expression levels in resting eggs, for trehalose-6-phosphate synthase (tps), fatty-acid binding proteins $(f a b)$ and of lipoprotein lipase $(l p l)$ and the aquaporins gene family (aqp). Changes in the expression pattern of some members of putative gene families occurred during the obligatory dormant period of resting eggs. A transition was observed from an expression pattern of diapausing embryos to an expression pattern of amictic females, during hatching. Differences were also found in the expression pattern in the different types of females, especially in those carrying resting eggs, and in males compared with females. These results suggest putative functional significance to genes associated with dormancy in non-desiccated resting eggs. It could also be proposed that their occurrence in resting eggs is developmentally programmed to facilitate survival in case of desiccation.

Keywords Rotifer resting egg - Transcriptome profiling - Gene expression

\section{Introduction}

Rotifers of the Brachionus species complex produce resting eggs that retain viability for decades in a dormant form (Kotani et al., 2001). The resting eggs 
are encased diapausing embryos and are produced after the onset of sexual reproduction in the rotifer Brachionus plicatilis (reviewed in Gilbert, 2007; see also Denekamp et al., 2009). They differ morphologically from the amictic or asexually produced eggs (Wurdak et al., 1978 and reviewed in Gilbert, 1989). The diapausing embryos will resume development and hatch after an obligatory dormant period, in response to specific cues such as light, temperature, salinity, hydrogen peroxide and prostaglandins (Minkoff et al., 1983; Hagiwara et al., 1995). The hatched eggs usually develop into asexually reproducing amictic females (FA), until they encounter a mixis signal directing them to embark on sexual reproduction. The factors inducing the mixis signal in the Brachionus species complex are largely unknown, although population density, salinity, temperature, presence of pheromones and food availability were found to play a role (Lubzens et al., 1985; Lubzens \& Zmora, 2003; Serra \& King, 1999; Gilbert, 2004a, 2007; Hagiwara et al., 2005; Snell et al., 2006; Denekamp et al., 2009).

The factors facilitating long-term survival of rotifer resting eggs have not been studied in detail. In some organisms the formation of dormant forms is associated with onset of stressful environmental conditions and they survive in a desiccated form (Berjak, 2006). Spores, seed plants and animal cysts display anabiosis or cryptobiosis, with extremely low metabolic rates and desiccation (Keilin, 1959; Clegg, 2001). In contrast, B. plicatilis resting eggs contain $\sim 70 \%$ water (Hagiwara, 1996) and they can survive desiccation by lyophylization after their water content is reduced to $\sim 7 \%$ ( Hagiwara, 1996; Balompapueng et al., 1997). In addition, the formation of $B$. plicatilis resting eggs is not always related to stress (reviewed in Schröder, 2005). Relatively few molecular studies have been performed on B. plicatilis and most of them were limited to single gene or protein studies (Wheelock et al., 2002; Kaneko et al., 2002, 2005). Recently, sequencing of the mitochondrial DNA (Suga et al., 2008) and EST resources (Suga et al., 2007; Denekamp et al., 2009) became available. In a previous study (Denekamp et al., 2009), an attempt was made to identify biological processes associated with dormancy in rotifers. Genes known to be associated with desiccation tolerance during dormancy in other organisms were identified in the EST libraries from rotifers, and some of the genes were found to show up-regulation in rotifer resting eggs by real-time RT-PCR (Denekamp et al., 2009). In this study (Denekamp et al., 2009), normalized and subtractive libraries were used to generate an EST transcriptome resource for $B$. plicatilis, consisting of a large number $(\sim 18,000)$ of putative transcripts. However, quantitative estimation of the expression levels for selected genes was not possible without further verification. The current study aims at providing a more in-depth view of the expression pattern of putative members of nine gene families during the sexual or asexual life cycles of rotifers and of resting eggs. The tested putative gene families include genes encoding for gluthatione- $S$-transferase (GST's), ferritin, $70 \mathrm{kDa}$ heat shock protein (HSP70), small heat shock proteins (SHSP), late embryogenesis abundant proteins (LEAs), trehalose-6-phosphate synthase (TPS), aquaporins (AQPs), lipoprotein lipase (LPLs) and fatty-acid binding proteins (FABs or lipocalins). A detailed description of the role of these proteins in dormant forms is found in Denekamp et al. (2009).

\section{Materials and methods}

\section{Rotifer samples}

Brachionus plicatilis individuals were hatched from resting eggs produced in the laboratory from individuals collected at a seaside pond in Atlit, (40 km south of Haifa, Israel) in 1981. Some of the resting eggs were hatched in 2003 and resting eggs produced from them were stored in the laboratory at $4^{\circ} \mathrm{C}$ and hatched in 2005. Sample collection has been described previously (Denekamp et al., 2009, 2010). Four different cultures were started, originating from four different batches of resting eggs. The cultures were started at an initial density of five females per $\mathrm{ml}$ in glass culture flasks containing $500 \mathrm{ml}$ culture medium, consisting of natural heat sterilized sea-water diluted with sterile distilled water to a salinity of 10 ppt. Rotifers were fed 0.5 million cells per one rotifer per day with Nannochloropsis sp. to induce mixis. Algae were cultured as previously described (Lubzens et al., 1995). Resting-egg producing females appeared after 4 days and their abundance in the following few days reached $10-15 \%$, relative to the number of all females in a specific culture. The abundance of resting-egg 
producing females decreased after 10-14 days to less than $1 \%$. The following is a detailed description of samples collected for RNA extraction and construction of cDNA libraries, prior to high-throughput sequencing by Illumina technology. Four biological replicates (from four different cultures) were collected and RNA extraction was performed on a total of 49 samples. A description of the cDNA libraries, their respective abbreviations (codes) and the number of biological replicates used for the construction of libraries is shown in Table 1.

\section{Collection of females}

Samples of amictic females (FA), mictic females carrying male eggs (FM) and mictic females carrying resting eggs (FRE) were manually picked from each culture, when the resting-egg production rate was at its peak. Each type of female was recognized by the eggs it carried and only females with eggs were manually collected. Briefly, FA amictic females were recognized by the relatively larger opaque eggs they carried,
FM mictic females carried small eggs and FRE mictic females carried larger opaque and dark coloured resting eggs and only FRE females with darker coloured eggs (compared with the amicitc eggs) were collected. About 2,000 individuals were collected for each replicate of the three types of females and suspended in fresh sterile seawater $(10 \mathrm{ppt})$. After collecting the appropriate number of females of each type, the females were sieved with $60 \mu \mathrm{m}$ plankton nets, washed with sterile diluted sea-water medium (10 ppt) and re-suspended in $10-15 \mathrm{ml}$ of sterile seawater (10 ppt) in a $15 \mathrm{ml}$ round bottom disposable vial. Ethanol was added to a final concentration of $10 \%$, the rotifers were centrifuged briefly $(2,000 \mathrm{RPM}$ for 1-2 $\mathrm{min}$ ) and the pelleted rotifers were collected into a $1.5 \mathrm{ml}$ Eppedorf tube. Subsequently, following brief centrifugation (2,000 RPM for $1 \mathrm{~min})$, the top liquid layer was removed and the pelleted rotifers were stored at $-70^{\circ} \mathrm{C}$ until use in RNA extraction procedure. The whole washing and pelleting procedure lasted less than $10 \mathrm{~min}$. The eggs were not removed from these females and the extraction was performed

Table 1 A list showing the code names of 13 different cDNA libraries and samples collected from rotifer life cycle stages

\begin{tabular}{llll}
\hline Number & Code & Description of sample & $\begin{array}{c}\text { Number of } \\
\text { biological } \\
\text { replicates }\end{array}$ \\
\hline 1 & FA & Amictic females from cultures producing resting eggs & 4 \\
2 & FRE & Mictic females carrying resting eggs & 4 \\
3 & FM & Micitc females carrying male eggs & 4 \\
4 & M & Males & 4 \\
5 & RE & Resting eggs, immediate RNA extraction ${ }^{\text {a }}$ & 4 \\
6 & RE +25 & Resting eggs stored in the dark, at $25^{\circ} \mathrm{C}$ for 3 months ${ }^{\text {a }}$ & 4 \\
8 & RE -70 & Resting eggs stored in the dark, at $-70^{\circ} \mathrm{C}^{\mathrm{a}}$ & 3 \\
9 & RE0 & Resting eggs used for hatching experiments, before exposure to light & \\
10 & RE15 & (at time 0$)^{\mathrm{b}}$ & 3 \\
11 & RE30 & Resting eggs after 15 h of exposure to light & \\
13 & AE & Resting eggs after 30 h of exposure to light & \\
\hline NRE & NRE.E & Amictic eggs & 4 \\
\hline
\end{tabular}

Biological replicate samples were collected from three or four different cultures, originating from different batches of resting eggs. Each replicate consisted of $\sim 2,000$ individuals in the case of females, or $\sim 5,000$ individuals in the case of males or eggs. RNA was extracted from each replicate and used as a template for cDNA synthesis. After evaluating the cDNA quality of each replicate, the cDNA from three or four replicates were pooled and used for Illumina sequencing

${ }^{a}$ Resting eggs produced in the same culture were used here and samples from four different cultures were used as biological replicates

b Resting eggs that were produced in one culture, were collected and used here for hatching experiments and samples were collected at 0,15 and $30 \mathrm{~h}$ after exposure to light. Samples from four different cultures were used as biological replicates 
with the females and the eggs they carried. This procedure was used for each of the three types of females.

\section{Collection of males}

Males (M) were collected from each culture by sequential sieving through plankton nets with the sizes of $250,120,80,60$ and $40 \mu \mathrm{m}$ to remove the larger females from the cultures. Females that remained in the sample were removed manually. The males were resuspended in sterile seawater $(10 \mathrm{ppt})$ and sieved through a $20-\mu \mathrm{m}$ plankton net, washed and re-suspended in $10-15 \mathrm{ml}$ sterile diluted sea-water medium (10 ppt). Ethanol was added to a final concentration of $10 \%$ and the males were then centrifuged (2,000 for 1-2 min) and the pellet was removed to a $1.5 \mathrm{ml}$ Eppendorf tube. Following brief centrifugation (2,000 rpm for $1 \mathrm{~min})$, the top liquid layer was removed and the pelleted rotifers were stored at $-70^{\circ} \mathrm{C}$ until their use in RNA extraction procedure. The whole washing and pelleting procedure lasted less than $10 \mathrm{~min}$. About 5,000 males were collected for each biological replicate.

\section{Collection of resting eggs}

Resting eggs were collected from the bottom layer of the culture flasks. Aliquots of $10 \mathrm{ml}$ collected from bottom layer were placed in a large Petri-dish and resting eggs were picked manually and removed from the amictic eggs and rotifers found in this layer. RNA was extracted immediately from some of them (sample $\mathrm{RE})$ and others were stored at $25^{\circ} \mathrm{C}$ in the dark for 3 months $(\mathrm{RE}+25)$, or at $-70^{\circ} \mathrm{C}$, in the dark (RE - 70), until their use in RNA extraction procedures. Eggs stored at $25^{\circ} \mathrm{C}$ for 3 months were used for the hatching experiments. Four biological replicate experiments were performed, with each replicate originating from resting eggs produced by a different culture. Hatching was initiated by exposing the resting eggs to light at $25^{\circ} \mathrm{C}$ and samples were taken after $0 \mathrm{~h}$ (RE0), $15 \mathrm{~h}$ (RE15) and $30 \mathrm{~h}$ (RE30) of exposure to light. The first rotifer hatched about $30 \mathrm{~h}$ after exposure to light. The hatching efficiency was $65.6 \%$ after $48 \mathrm{~h}(N=3)$. Hatching did not continue after $48 \mathrm{~h}$ from the initial exposure to light. Three replicates were used for the hatching experiments (see Table 1). About 5,000 resting eggs were used for RNA extraction from each biological replicate sample.
Collection of amictic eggs

Amictic females (FA) were collected as described above. The amictic eggs (AE) were collected by intensive up and down movement with a $5 \mathrm{ml}$ pipette tip ('re-pipetting'), of $5 \mathrm{ml}$ samples containing amictic females that were suspended in a small volume of seawater. In this way, the amictic eggs were shed from the females and could be collected from the bottom of the vial. They were manually cleaned from newborn females that continuously hatched from the eggs. Hatching of the amictic eggs was stopped by adding ethanol (10\% final concentration), whereby the eggs settled at the bottom of a vial, the supernatant was removed, and the sample was frozen in liquid nitrogen. The eggs were stored at $-70^{\circ} \mathrm{C}$ until RNA extraction. About 5,000 eggs were used for RNA extraction from each biological replicate sample.

\section{Collection of amictic females and amictic eggs from a clone not showing sexual reproduction (Clone NRE)}

Rotifers in some of the clonal cultures that were formed from resting eggs (produced in 2005, see above), could not be experimentally induced to produce males or resting eggs. These amictic females (NRE) and their amictic eggs (NRE.E) were collected as described in 'Collection of females' section for amictic females and 'Collection of amictic eggs' section, for amictic eggs, respectively.

\section{Library construction and sequencing}

RNA was extracted from 13 different stages of development (see Table 1) with the TRIzol reagent (Invitrogen).Total RNA from four biological replicates per stage was pooled (equal amounts from each replicate), after measurement and quality control. An amount of $1.5 \mu \mathrm{g}$ of total RNA was used as template for cDNA synthesis, by the Mint cDNA synthesis kit (Evrogen, Russia) following the manufacturer instructions. The amplified cDNA was purified (QIAquick PCR Purification Kit, Qiagen). The cDNA was measured and quality checked by gel-electrophoreses. An amount of at least $8 \mu \mathrm{g}$ cDNA per replicate with a size distribution between 0.5 and $3 \mathrm{kbp}$ was obtained. Library generation and sequencing were performed using the Illumina sequencing platform (Genome 
Analyzer, Illumina) according to the manufacturer's instructions for shotgun sequencing. In total, 13 libraries were generated for sequencing (see Table 1) consisting of amictic females (FA), amicitc eggs (AE), mictic females with resting eggs (FRE), resting eggs (RE), females with haploid male eggs (FM), males (M), resting eggs stored at $25^{\circ} \mathrm{C}$ or $-70^{\circ} \mathrm{C}$ ( $\mathrm{RE}+25, \mathrm{RE}-70$, respectively), resting eggs during hatching at time 0,15 and $30 \mathrm{~h}$ (RE0, RE15, RE30, respectively) and amictic females (NRE) and their eggs (NRE.E) from a clonal culture that do not produce resting eggs. It should be emphasized that each sequenced library represents about 6,000 rotifers for female libraries and about 15,000 individuals for amictic eggs, resting eggs or male libraries.

Analyses of data from Illumina sequencing

Analysis of reads

Sequences were extracted using Gerald which comes with Illumina Pipeline v1.0 with all possible basecalls and with standard QC turned on (chastity filter $\geq 0.6$ ). The sequences (reads) from the 13 different libraries were aligned against rotifer $\sim 18,000$ EST sequences (see Denekamp et al., 2009) using SOAP (Li et al., 2008, v1.11) allowing two mismatches within 32 bp. Prior to that, reads containing more than two Ns were filtered and discarded. For each library, the sum of all aligned reads of their specific contig is calculated (this equals to transcripts in this case), not keeping track of the uniqueness. A read can align up to 25 times before it gets completely discarded since the full transcriptome sequence is unknown and it is not possible to make any splice junction analysis/discovery of novel junctions as it is the standard procedure with mouse or human sequencing. Because the number of total reads in a library varied between libraries (due to technical differences stemming from PCR amplification, library preparation, sequences cluster generation etc.), a simple scaling method was used to facilitate comparisons between them. In comparing two libraries, for example, it consisted of calculating a factor of the aligned reads between the two libraries and multiplying one library to the level of the other. The analysis for differential expression was done via R/Bioconductor with standard chi-square test, Fisher exact test and a self implemented version of Audic and Claveries bayesian approach (Audic \& Claverie, 1997). A transcript was considered to be changed differentially if it matched the following cases:

- state $1 /$ state $2 \leq 0.5$ OR state $1 /$ state $2 \geq 2.0$

- $\#\{$ reads.state 1$\} \geq 50$ OR \#\{reads.state $\} \geq 50$

- one of the three statistical test $P$-values $\leq 0.01$

The relatively high present read filter level (50 for one of the states) is caused by the very high read coverage of $\sim 2 \mathrm{Gbp}$ per lane compared to only $\sim 14 \mathrm{Mbp}$ of the whole rotifer transcriptome, which yields a theoretical factor of $\sim 142 \times$.

\section{The relative abundance of transcripts}

The relative abundance of a transcript for each putative gene paralog in the data set generated by Illumina sequencing (after performance of scaling) was calculated as follows:

$$
\mathrm{RA} i=\log _{2}\left(\mathrm{R}_{n x} / \sum R_{n x-n x 13}\right)
$$

where RA $i$ is the relative abundance of reads for gene $i, R_{\mathrm{nx}}$ is the number of reads for transcript $i$ in a library $x,(x=1,2,3 \ldots 0.13)$ and $\sum R_{n x-n x 13}$ is the sum of all reads for transcript $i$ in the 13 libraries. The relative abundance for nine putative genes and their paralogs is shown as a heat-map in Fig. 1 of the 'Results' section.

\section{Real-time RT-PCR}

In order to verify the results from Illumina sequencing, real-time PCR was performed on 12 gene transcripts with three out of the four biological replicate RNA samples that were used for construction and sequencing of the 13 cDNA libraries (see 'The relative abundance of transcripts' section above). A detailed description and results are shown in ESM File 1.

\section{Results}

High-throughput Illumina sequencing was used to discern the expression pattern of putative genes coding for nine gene families in this study. Regression analyses (Fig. S1; Pearson $r=0.94$ ) revealed a high correlation between expression values obtained by real-time RT-PCR and the number of reads (sequences) for each transcript in the libraries (for the 

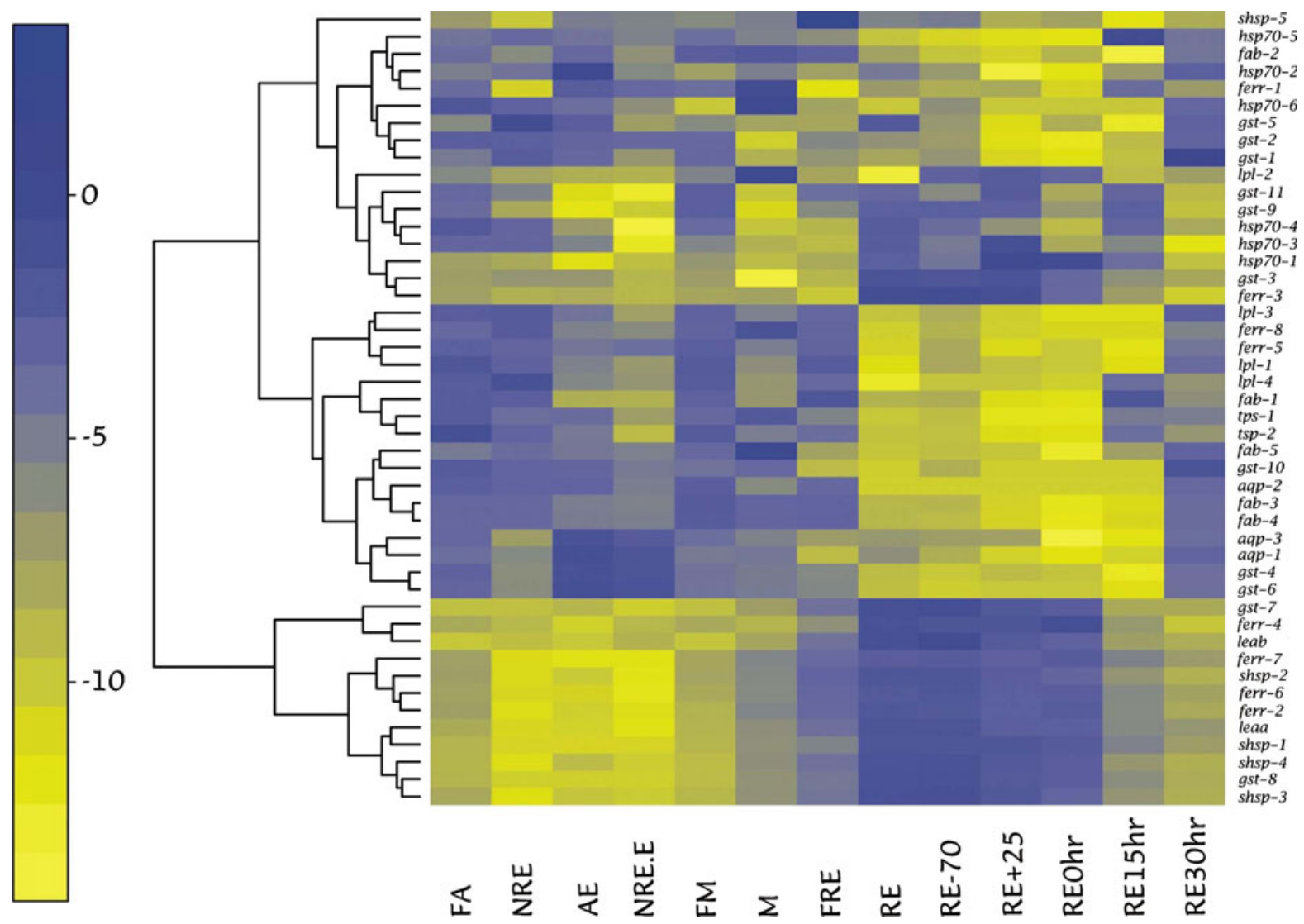

Fig. 1 A heatmap showing the relative abundance of read counts (in $\log 2$ units) of selected genes in: amictic females (FA), amictic females from a clonal culture not producing resting-eggs (NRE), amictic eggs (AE), amictic eggs from a clonal culture not producing resting-eggs (NRE.E), mictic females carrying male eggs (FM), mictic females carrying resting-eggs (FRE), resting eggs (RE), resting eggs that were stored at $-70^{\circ} \mathrm{C}(\mathrm{RE}-70)$, resting eggs that were stored at $25^{\circ} \mathrm{C}(\mathrm{RE}+25)$, resting eggs during hatching at $t=0 \mathrm{~h}$ (RE0hr), resting eggs during hatching at $t=15 \mathrm{~h}$ (RE15hr), resting eggs during hatching at $t=30 \mathrm{~h}$ (RE30hr). The genes

full details for these experiments see ESM File 1). These results verify that the high-throughput Illumina sequencing results shown as reads reflect appropriately the expression pattern of genes in the samples tested in this study.

Each gene family consists of several putative paralogs, including 11 putative paralogs of glutathione-S-transferase ( $g$ st), six putative paralogs of HSP70 ( $h s p 70$ ), five putative paralogs of small heat shock (shsp), eight putative paralogs of ferritin (ferr), two putative paralogs encoding the LEAs (lea), two coding for the following proteins were selected are: glutathione-S-transferase (gst-1 to gst-11), ferritin (ferr-1 to ferr-8), small heat shock proteins (shsp-1 to $s h s p-5$ ), late embryogenesis abundant protein (lea-1 and lea-2), trehalose-6-phosphate synthase (tps-1 and tps-2), aquaporins (aqp-1, aqp-2 and aqp3), heat shock proteins 70 ( $h s p 70-1$ to $h s p 70-6$ ), lipoprotein lipase (lpl-1 to $l p l-4$ ) and lipocalins (fatty-acid binding proteins; $f a b-1$ to $f a b-5)$. The associations of expression patterns of the different putative gene paralogs, is shown by the cluster analysis on the left side of the heatmap

putative paralogs of trehalose-6-phosphate synthase $(t p s)$, three putative paralogs of aquaporin (aqp), four putative paralogs of lipoprotein lipase $(l p l)$ and five putative paralogs coding for the fatty-acid binding proteins $(f a b)$.

Basically three patterns of gene expression were revealed by cluster analysis for the nine gene families (Fig. 1): (a) genes mainly expressed in resting eggs; (b) genes mainly expressed in females and in resting eggs at the end of the hatching period; and (c) genes with variable patterns of expression. 
Genes showing higher expression patterns in resting eggs

Resting eggs show clearly specific higher expression levels for genes coding LEA proteins (lea-1 and-lea2; Fig. 1). Also, four out of five paralogs of the gene coding for putative small heat shock proteins (shsp-1, shsp-2, shsp-3 and shsp-4) show relatively high expression levels in resting eggs. In addition, five paralogs of the ferritin family show higher expression patterns in resting eggs; ferr-2, ferr-3, ferr-4, ferr-6 and ferr-7 (Fig. 1).

Three members of the glutathione- $S$-transferase family ( $g s t-3$, gst-7 and $g s t-8$; Fig. 1), were more abundant in all non-hatched resting eggs libraries. The expression levels of $g s t-9$ and of $g s t-11$ were relatively high in some of the resting egg libraries, but both were lower in the library of resting eggs (RE0) that were collected after the obligatory period of dormancy and before hatching. Non-stored resting eggs showed relatively a high expression level for gst-5, but the level of expression for this gene was reduced after storage. Two putative paralogs, $h s p 70$ land $h s p 70-3$, show high expression levels in resting egg and others (e.g. $h s p 70-2, h s p 70-5$ and $h s p 70-6$ ) show relatively higher expression levels in amictic eggs or hatching resting eggs (RE15 and RE30).

Genes showing lower expression levels in resting eggs

Several genes show lower expression pattern in resting eggs. These include two putative members of the trehalose-6-phosphate synthase family (tps-1 and tps-2; Fig. 1) and three putative members of the aquaporin family (aqp-1, aqp-2 and $a q p-3$; Fig. 1). In addition, three putative paralogs of the putative lipoprotein lipase gene group (lpl-1, lpl-3 and $l p l-4$ ) and the five paralogs of the genes encoding fatty-acid binding proteins ( $f a b-1-5)$ also showed relatively low expression patterns in resting eggs. For members of the ferritin family, the expression of ferr-1, ferr-5 and ferr- 8 was lower in resting eggs (Fig. 1).

Changes in expression pattern in stored resting eggs and during hatching

There is a clear transition from the expression pattern of diapausing embryos to an expression pattern of amictic females during hatching, in almost all expressed putative gene families (with few exception such as $h s p 70-3, h s p 70-4$, and ferr-1, gst-9 and gst11; Fig. 1). The pattern of expression for most gene families coding for small heat shock proteins, LEA proteins, trehalose-6-phosphate synthase, fatty-acid binding proteins (lipocalins) and lipoprotein lipase, did not change during storage (compare patterns of $\mathrm{RE}, \mathrm{RE}+25, \mathrm{RE}-70$ and RE0). Some exceptions include the lower expression levels in resting eggs after the obligatory diapause period, of putative paralogs of $h s p 70$ gene family (especially $h s p 70-3$ and $h s p 70-4)$ and of member of the aquaporins gene family (aqp-1, aqp-2 and $a q p-3)$.

Expression patterns in females and males

There were noticeable differences between mictic females carrying resting eggs (FRE) and amictic females (Fig. 1). Some differences could be accounted by the gene expression pattern of resting eggs. Still, a few transcripts differ specifically in these FRE females and these include mainly lower expression pattern for transcripts coding for HSP70 ( $h s p 70-2, h s p 70-3$ and $h s p 70-4)$ and glutathione-S-transferase (gst-5). Interestingly, FRE females show higher expression for shsp-5.

In general, the pattern of expression of amictic females (FA) in a culture producing resting eggs did not differ from that of amictic females (NRE) of a clonal culture that do not produce resting eggs. There were some exceptions including a lower expression pattern in aqp-1, aqp-3, ferr-1 and $g s t-4$, gst-6 and gst-9. Relatively lower expression patterns were found in the eggs (NRE.E) carried by amictic females in transcripts coding for HSP70 ( $h s p 70-3$ and $h s p 70-4$ ), trehalose-6-phosphate synthase (tps-1 and $t p s-2)$ and glutathione-S-transferase (gst-1 and gst-5).

The expression pattern for genes in mictic females carrying male eggs (FM) was similar to that of amictic females (FA), except for higher expression of $a q p-1$ and $a q p-3$. In males, a general lower expression pattern was observed for transcripts coding for HSP70, glutathione-S-transferase and lipoprotein lipases (Fig. 1). Interestingly, the expression of $l p l-2$ was specifically higher in males. 


\section{Discussion}

In a previous study, we showed that gene families consisted often of several putative members, differing in their matching sequences and supporting a contention that they may represent paralog genes. The multiple numbers of putative paralogs for some genes may indicate gene duplication during evolution. It has been proposed that functionality of duplicated genes can be maintained through variability in spatial and temporal expression patterns, but subfunctionality or neofunctionality are also an option (Force et al., 1999; Lynch \& Force, 2000; Kondrashov \& Kondrashov, 2006). In yeast, higher sharing of transcription factors by duplicated genes was generally observed but for certain gene pairs, multidimensional functional differentiation were reported (Hughes \& Friedman, 2007). Although we classify members of one gene family as putative paralog genes, the differences between them could also stem from spliced junctions and resolving this question awaits full length sequencing.

Basically three patterns of gene expression were revealed by cluster analysis for the nine gene families studies here (Fig 1): (1) genes mainly expressed in resting eggs; (2) genes mainly expressed in females and in resting eggs at the end of the hatching period; and (3) genes with variable patterns of expression. It should be noted that the gene expression patterns of females carrying amictic eggs (FA, NRE) or resting eggs (FRE) could be partially attributed to the eggs they carry. However, some degree of distinction, between gene expression patterns of females to those of their eggs could be discerned from the pattern of gene expression of the isolated amcitic or resting eggs. For example, gst-5 is relatively highly expressed in RE but not in FRE or $g s t-9$ that is relatively highly expressed in FA but not in AE. In addition, as hatching started about $30 \mathrm{~h}$ after initiation of hatching by light, some of the resting eggs may contain almost fully formed amictic females and this is reflected in the resemblance of expression profiles of RE30 to those of amictic females (Fig. 1). In general, the results suggest some different spatial and temporal expression patterns of putatively duplicated genes (see also Lynch \& Force, 2000).
Genes showing higher expression patterns in resting eggs

Genes coding for LEA proteins (lea-1 and-lea-2; Fig. 1) showed clearly higher expression levels in resting eggs similar to results of a previous study where they were found highly expressed in resting eggs and females carrying resting eggs (Denekamp et al., 2009, 2010). Recently, full cDNA sequencing revealed only two transcripts for LEA in rotifers, as the sequence of lea-2 was found to contain the sequence of lea-3 (Denekamp et al., 2010). The rotifer LEA proteins belong to Group 3 LEA proteins and in order to avoid confusion were renamed as leaa corresponding with lea-1 and leab, corresponding with lea-2 (Denekamp et al., 2010). LEA proteins are associated with desiccation tolerance throughout the life cycle of major plant taxa and especially in seeds. They have been found also in non-plant species (nematodes, bdelloid rotifers, Artemia cysts, springtail insects) and almost all non-plant LEA proteins belong to Group 3 (Tunnacliffe \& Wise, 2007; Clark et al., 2007), although a Group 1 LEA protein was recently reported in Artemia cysts (Sharon et al., 2009). The exact functions of LEAs are not completely known but they were shown to play a role in protein stabilization, prevent protein aggregation (Chakrabortee et al., 2007) and participate in the intracellular glassy state formation during desiccation in orthodox seeds (Berjak, 2006).

Four out of five paralogs of the gene coding for putative small heat shock proteins (shsp-1, shsp-2, shsp-3 and shsp-4) also showed relatively high expression levels in resting eggs. These generally support previous results (Denekamp et al., 2009), where 55 transcripts constituting $\sim 4.5 \%$ of the total number of sequenced clones in a resting egg subtractive library, were found for shsp-2, shsp-3, shsp-4 and shsp-5 (but not for shsp-1). Small heat shock proteins are specifically abundant in Artemia cysts and presume to function in maintaining the native folded structure of proteins (Chen et al., 2007).

The expression of a large number of genes protecting against reactive oxygen species (ROS) species has been observed in dormant forms as ROS are continuously produced even during dormancy. Moreover, resumption of full metabolic (e.g. hatching of resting 
eggs) involves a large, sometimes sudden, increase in oxygen uptake and ROS generation. Maintaining high constitutive anti-oxidative defences is one way of coping with these phenomena (Walters et al., 2005; Storey \& Storey, 2007; Bailly et al., 2008). Consequently, five paralogs of the ferritin family show higher expression patterns in resting eggs; ferr-2, ferr-3, ferr4, ferr-6 and ferr-7 (Fig. 1). Ferritin is the intracellular protein responsible for the sequestration, storage and release of iron. There are strong links between ferritins, protection against oxidative stress and coping with adverse conditions (Briat et al., 2009).

Glutathione- $S$-transferases (GSTs) belong to a superfamily of multifunctional proteins with fundamental roles in cellular detoxification and removal of xenobiotics (Frova, 2006). Members of this gene family show a complicated pattern of expression in the current study. Three members of the glutathione$S$-transferase family (gst-3, gst-7 and gst-8; Fig. 1), were more abundant in all non-hatched resting eggs libraries. The expression levels of $g s t-9$ and of $g s t-11$ were relatively high in some of the resting egg libraries, but both were lower in the library of resting eggs (RE0) that were collected after the obligatory period of dormancy and before hatching. Non-stored resting eggs showed relatively a high expression level for gst-5, but the level of expression for this gene was reduced after storage. Several gst putative paralogs were highly expressed in females but not in males. Interestingly, five of the putative rotifer GSTs show closest sequence matches to C. elegans functioning in electrophilic stress (Ayyadevara et al., 2007).

Members of the $h s p 70$ gene family also demonstrate a complicated pattern of expression. Some putative gene paralogs show relatively higher expression levels in resting eggs or resting eggs during hatching and others in amictic females or amictic eggs. Two putative paralogs, $h s p 70-1$ and $h s p 70-3$, show high expression levels in resting egg and others (e.g. $h s p 70-2, h s p 70-5$ and $h s p 70-6$ ) show relatively higher expression levels in amictic eggs or hatching resting eggs (RE15 and RE30). Interestingly, very low expression levels for putative $h s p 70$ gene family members were found in females carrying resting eggs (Fig. 1). Members of the HSP70 superfamily are associated with classical cellular stress response and during starvation in rotifers. In an orthopteran parasite they were reported to be associated with diapause (discussed in Denekamp et al., 2009).
Genes showing lower expression levels in resting eggs

The expression patterns for several genes that were found to be associated with dormancy in other organisms show lower expression in rotifer resting eggs. These include two putative members of the trehalose-6-phosphate synthase family (tps- 1 and tps2 ), three putative members of the aquaporin family (aqp-1, aqp-2 and aqp-3), three putative paralogs of the putative lipoprotein lipase gene group (lpl-1, lpl-3 and $l p l-4)$ and the five paralogs of the genes encoding fatty-acid binding proteins $(f a b-1-5)$. It is assumed that trehalose plays an important role in enhancing tolerance to desiccation and stress in nematodes (Pellerone et al., 2003), Artemia cysts (Crowe \& Crowe, 2000), springtail insects (Clark et al., 2007 and others). They were suggested to participate in the formation of the glassy state during desiccation (reviewed in Berjak, 2006). Small amounts of trehalose were found in B. plicatilis desiccated resting eggs (Caprioli et al., 2004) and a transcript with high sequence similarity to tps was reported by Suga et al. (2007). The results show relatively low gene expression profiles in resting eggs (but high gene expression profiles in all types of females) and raise a question regarding the putative role of trehalose in rotifer resting eggs, as trehalose was not found in desiccated bdelloid rotifers (Tunnacliffe et al., 2005). A low correlation was reported for desiccation tolerance and trehalose levels in several organisms, including Arabidopsis, bacteria and yeast (see Discussion in Avonce et al., 2004). Arabidopsis, over-expressing AtTPS1 accumulated only low levels of trehalose but these transgenic plants have acquired desiccation tolerance. It was suggested by these authors that the low trehalose levels were sufficient for its action as an osmoprotectant. A similar role for trehalose in rotifer resting eggs could be suggested but this has not been experimentally shown so far.

The role of aquaporins in rotifer resting eggs is also not clear, as these trans-membrane proteins serve for transporting water and small soluble molecules and were found to play a role in desiccation in seeds (Plenzler, 2006). Here, a possible role is suggested for aquaporins, but this requires additional verification, since the exact assignment of their sequences to the aquaporin family members was difficult (Denekamp et al., 2009). 
Dormancy has been associated with a function for lipids and lipid metabolism and lipid droplets were reported to occur in rotifer resting eggs (Wurdak et al., 1978). Lipid metabolic pathways were upregulated in the dormant dauer stage of $C$. elegans (Wang \& Kim, 2003) and lipids serve as the main energy source during hibernation (Storey, 2003; Dark, 2005). Higher levels of fatty-acid binding proteins, known for their role in transport function of long chain fatty acids were reported in the liver of hibernating squirrels (Epperson et al., 2004). The results shown here do not support a significant role for paralogs of $f a b$ 's or lpl's (except $l p l-2$ ) in resting eggs. It is possible though that the lipids or specific fatty acids are synthesized by the mothers are deposited in the eggs during their formation within the vitellarium. While, unexpectedly, Pauwels et al. (2007) did not find differences in the triglycerol content between subitaneous and dormant eggs, newborn stem Brachionus calyciflorus females (hatching from resting eggs) had many more lipid droplets (probably neutral-lipid storage products) in their tissues than similar sized newborn females from parthenogenic eggs (Gilbert, 2004b).

It is interesting to note that three members of the ferritin family (ferr-1, ferr-5 and ferr-8) show lower expression patterns in resting eggs (Fig. 1) and its functional significance will need to await additional studies.

Changes in expression pattern in stored resting eggs and during hatching

A clear transition from an expression pattern of diapausing embryos to an expression pattern of amictic females was observed during hatching, in almost all expressed putative gene families (with few exception as mentioned in 'Changes in expression pattern in stored resting eggs and during hatching' section above). Some of the variation observed in gene expression pattern could be attributed to the fact that samples after 15 or $30 \mathrm{~h}$ of initiating hatching, contained unhatched diapausing embryos. The pattern of expression for most gene families coding for small heat shock proteins, LEA proteins, trehalose 6-phosphate synthase, fatty-acid binding proteins (lipocalins) and lipoprotein lipase did not change during storage. Some exceptions include the lower expression levels in resting eggs after the obligatory diapause period, of putative paralogs of $h s p 70$ gene family and of members of the aquaporins family. The functional significance of these differences cannot be explained at this stage but it maybe speculated that they form part of a suite of genes associated with the hatching response to an external cue (e.g. light) and this could be a direction for future research.

Expression patterns in females and males

Differences in gene expression patterns were noticed between mictic females carrying resting eggs (FRE) and amictic females (Fig. 1). While some differences could be accounted by the gene expression pattern of resting eggs, a few transcripts differ specifically in these FRE females and these include mainly lower expression pattern for transcripts coding for HSP70 (hsp70-2, hsp70-3 and hsp70-4) and glutathione$S$-transferase (gst-5). Interestingly, FRE females show higher expression for shsp-5 but the significance of these differences is not clear at this stage. In general, the pattern of expression of amictic females (FA) in a culture producing resting eggs did not differ from that of amictic females (NRE) of a clonal culture that do not produce resting eggs. There were some exceptions including a lower expression pattern in aqp- 1 and aqp-3. Similarly, small differences were found between amictic eggs carried by females of the clonal culture that do not produce resting eggs and the amictic eggs in a culture producing resting eggs. These include, relatively lower expression patterns in transcripts coding for HSP70 (hsp70-3 and $h s p 70-4$ ), trehalose-6-phosphate synthase (tps-1 and tps-2) and glutathione- $S$-transferase (gst- 1 ).

The expression pattern for genes in mictic females carrying male eggs (FM) was similar to that of amictic females (FA), except for higher expression of aqp-1 and aqp-3. In males, a general lower expression pattern was observed for transcripts coding for HSP70, glutathione- $S$-transferase and lipoprotein lipases (Fig. 1). Interestingly, the expression of $l p l-2$ is specifically higher in males, possibly indicating higher lipid hydrolysis. It is well known that $B$. plicatilis males do not have a functional gut and do not feed and their metabolism must rely on stored nutrients, possibly lipids.

In conclusion, the study suggests a specific role for LEA proteins and shsp's in rotifer resting eggs. 
The multiple expression patterns of paralogs coding for ferritin, hsp70 and gst's suggests also specific roles for some putative gene paralogs in resting eggs and for others, in females. The roles of trehalose, aquaporins, fatty-acid binding proteins and lipoprotein lipase could not be verified for resting eggs by transcriptome analyses, but this does not rule out the possibility of regulation at the translational level. Changes in gene expression pattern of some genes occurred during the obligatory dormant period. Differences were also found in the expression pattern of the nine tested putative gene families in the different types of females and in males. The occurrence of putative multiple paralogs for gene families reported here, with variable expression patterns in different females, males, amictic females and resting eggs could support the proposition of multiple functionality arising subsequent to gene duplication (Force et al., 1999; Lynch \& Force, 2000). Whereas this study can provide a new insight into their function that could not be discerned from previous results (Denekamp et al., 2009), it raises a question regarding the mode of regulation of multiple gene paralogs. This question is difficult to be addressed at this stage of the investigation due to lack of adequate genomic and functional information.

The results suggest putative functional significance to genes associated with dormancy in the nondesiccated resting eggs. It can be proposed that their occurrence in resting eggs is developmentally programmed to facilitate survival in the case of encountering desiccation or alternatively, these genes may function in preserving the viability of the hydrated form of resting eggs. Hopefully, this study will assist in directing future research endeavours in ascertaining gene function and biological processes during the onset of sexual reproduction, formation of resting eggs, dormancy in non-desiccated resting eggs and those involved in the obligatory dormant period before hatching.

Acknowledgements This study was supported by the European Commission (NEST \#12674; Sleeping Beauty). The technical help of Irena Perkaski and Alisa Hadani is highly appreciated. We acknowledge the Illumina sequencing by the ngs-group of MPI-MG. We would also like to thank two anonymous reviewers for their useful comments and Dr. M. S. Clark (British Antarctic Survey, Natural Environment Research Council, Cambridge, UK) for useful discussions.

\section{References}

Audic, S. \& J. M. Claverie, 1997. The significance of digital gene expression profiles. Genome Research 7: 986-995.

Avonce, N., B. Leyman, J. O. Mascorro-Gallardo, P. Van Dijk, J. M. Thevelein \& G. Iturriaga, 2004. The Arabisopsis trehalose-6-P synthase AtTPS1 gene is a regulator of glucose, abscisic acid, and stress signaling. Plant Physiology 136: 3649-3659.

Ayyadevara, S., A. Dandapat, S. P. Singh, E. R. Siegel, R. J. Shmookler Reis, L. Zimniak \& P. Zimniak, 2007. Life span and stress resistance of Caenorhabditis elegans are differentially affected by glutathione transferases metabolising 4-hydroxynon-2-enal. Mechanisms of Ageing and Development 128: 196-205.

Bailly, C., H. El-Maarouf-Bouteau \& F. Corbineau, 2008. From intracellular signaling networks to cell death: the dual role of reactive oxygen species in seed physiology. C.R. Biologies 331: 806-814.

Balompapueng, M. D., A. Hagiwara, Y. Nozaki \& K. Hirayama, 1997. Preservation of resting eggs of the euryhaline rotifer Brachionus plicatilis O.F. Müller by canning. Hydrobiologia 358: 163-166.

Berjak, B., 2006. Unifying perspectives of some mechanisms basic to desiccation tolerance across life forms. Seed Science Research 16: 1-15.

Briat, J.-F., K. Ravet, A. Nicolas, C. Duc, J. Voucherez, B. Touraine, F. Cellier \& F. Gaymard, 2009. New insights into ferritin synthesis and function highlight a link between iron homeostasis and oxidative stress in plants. Annals of Botany 105(5): 811-822.

Caprioli, M., A. K. Katholm, G. Melone, H. Ramlov, C. Ricci \& N. Santo, 2004. Trehalose in desiccated rotifers: a comparison between a bdelloid and a monogonont species. Comparative Biochemistry and Physiology A 139: 527-532.

Chakrabortee, S., C. Boschetti, L. I. Walton, S. Sarkar, D. Rubinsztein \& A. Tunnacliffe, 2007. Hydrophilic protein associated with desiccation tolerance exhibits broad protein stabilization function. Proceedings of the National Academy of Science 104: 18073-18078.

Chen, T., T. S. Villeneuve, K. A. Garant, R. Amons \& T. H. MacRae, 2007. Functional characterisation of artemin, a ferritin homolog synthesised in Artemia embryos during encystment and diapause. The FEBS Journal 274: 1093-1101.

Clark, M. S., M. A. Thorne, J. Purać, G. Grubor-Lajsić, M. Kube, R. Reinhardt \& M. R. Worland, 2007. Surviving extreme polar winters by desiccation: clues from Arctic springtail (Onychiurus arcticus) EST libraries. BMC Genomics 8: 475.

Clegg, J. S., 2001. Cryptobiosis - apecular state of biological organization. Comparative Physiology and Biochemistry Molecular Biology 128: 613-624.

Crowe, J. H. \& L. M. Crowe, 2000. Preservation of mammalian cells - learning nature's tricks. Nature Biotechnology 18 : $145-146$.

Dark, J., 2005. Annual lipid cycles in hibernators: integration of physiology and behavior. Annual Review of Nutrition 25: 469-497. 
Denekamp, N. Y., M. A. S. Thorne, M. S. Clark, M. Kube, R. Reinhardt \& E. Lubzens, 2009. Discovering genes associated with dormancy in the monogont rotifer Brachionus plicatilis. BMC Genomics 10: 108.

Denekamp, N. Y., M. Kube, R. Reinhardt \& E. Lubzens, 2010. Presence of Late embryogenesis abundant (LEA) proteins in a non-desiccated, diapausing invertebrate embryo. Biology of Reproduction 82: 714-724.

Epperson, L. E., T. A. Dahl \& S. L. Martin, 2004. Quantitative analysis of liver protein expression during hibernation in the golden-mantled ground squirrel. Molecular and Cellular Proteomics 3: 920-933.

Force, A., M. Lynch, F. B. Pickett, A. Amores, Y. Yan \& J. Postlethwait, 1999. Preservation of duplicate genes by complementary, generative mutations. Genetics 151: 1531-1545.

Frova, C., 2006. Glutathione transferases in the genomics era: new insights and perspectives. Bioengineering 23: 149-169.

Gilbert, J. J., 1989. Rorifera. In: Reproductive biology of invertebrates. In Adiyodi, K. G. \& R. G. Adiyodi (eds), Sexual differentiation and behaviour, Vol V. Oxford \& IBH Publishing Co. Pvt. Ltd, New Delhi: 115-136.

Gilbert, J. J., 2004a. Population density, sexual reproduction and diapause in monogonont rotifers: new data for Brachionus and a review. Journal of Limnology 63(Suppl 1): 32-36.

Gilbert, J. J., 2004b. Females from resting eggs and parthenogenic eggs in the rotifer Brachionus calyciflorus: lipid droplets, starvation resistance and reproduction. Freshwater Biology 49: 1505-1515.

Gilbert, J. J., 2007. Timing of diapause in monogonont rotifers: mechanisms and strategies. In Alekseev, V. R., B. De Stasio \& J. J. Gilbert (eds), Diapause in Aquatic Invertebrates: Theory and Human Use. Springer, Dordrecht: 11-27.

Hagiwara, A., 1996. Use of resting eggs for mass preservation of marine rotifers. Technical Reports of Japanese Sea Ranching Programs 24: 109-120. (In Japanese).

Hagiwara, A., N. Hoshi, F. Kawahara, K. Tominaga \& K. Hirayama, 1995. Resting eggs of the marine rotifer Brachionus plicatilis Muller: development and effect of irradiation on hatching. Hydrobiologia 313(314): 223-229.

Hagiwara, A., Y. Kadota \& A. Hino, 2005. Maternal effect by stem females in Brachionus plicatilis: effect of starvation on mixis induction in offspring. Hydrobiologia 546: 275-279.

Hughes, L. A. \& R. Friedman, 2007. Sharing of transcription factors after gene duplication in the yeast Saccharomuces cerevisiae. Genetica 129: 301-308.

Kaneko, G., S. Kinoshita, T. Yoshinaga, K. Tsukamoto \& S. Watabe, 2002. Changes in expression patterns of stress protein genes during population growth of the rotifer Brachionus plicatilis. Fisheries Sciences 68: 1317-1323.

Kaneko, G., T. Yoshinaga, Y. Yanagawa, S. Kinoshita, K. Tsukamoto \& S. Watabe, 2005. Molecular characterization of Mn-superoxide dismutase and gene expression studies in dietary restricted Brachionus plicatilis rotifers. Hydrobiologia 546: 117-123.
Keilin, D., 1959. The problem of anabiosis of latent life: history and current concept. Proceedings of the Royal Society Biological Sciences 150: 149-191.

Kondrashov, F. A. \& A. S. Kondrashov, 2006. Role of selection in fixation of gene duplications. Journal of Theoretical Biology 239: 141-151.

Kotani, T., M. Ozaki, K. Matsuoka, T. W. Snell \& A. Hagiwara, 2001. Reproductive isolation among geographically and temporally isolated marine Brachionus strains. Hydrobiologia 446(447): 283-290.

Li, R., Y. Li, K. Kristiansen \& J. Wang, 2008. SOAP: short oligonucleotide alignment program. Bioinformatics 24 : 713-714.

Lubzens, E. \& O. Zmora, 2003. Production and nutritional value of rotifers. In Stottrup, J. G. \& L. A. McEvoy (eds), Live Feeds in Marine Aquaculture. Blackwell Publishing, Oxford: 17-64 (Appendix I 300-303).

Lubzens, E., G. Minkoff \& S. Marom, 1985. Salinity dependence of sexual and asexual reproduction in the rotifer Brachionus plicatilis. Marine Biology 85: 23-126.

Lubzens, E., O. Gibson, O. Zmora \& A. Sukenik, 1995. Potential advantages of frozen algae (Nannochloropsis sp.) for rotifer (Brachionus plicatilis) culture. Aquaculture 133: 295-309.

Lynch, M. \& A. Force, 2000. The probability of duplicate gene preservation by subfunctionalization. Genetics 154: 459-473.

Minkoff, G., E. Lubzens \& D. Kahan, 1983. Environmental factors affecting hatching of rotifer (Brachionus plicatilis) resting eggs. Hydrobiolgia 104: 61-169.

Pauwels, K., R. Stoks, A. Verbiest \& L. De Meester, 2007. Biochemical adaptation for dormancy in subitaneous and dormant eggs of Daphnia magna. Hydrobiologia 594: 91-96.

Pellerone, F. L., S. K. Archer, C. A. Behm, W. N. Grant, M. J. Lacey \& A. C. Somerville, 2003. Trehalose metabolism genes in Caenorhabditis elegans and filarial nematodes. International Journal of Parasitology 33: 1195-1206.

Plenzler, G., 2006. Presence of aquaporins in desiccation process in pea seeds. Acta Agrophysica 7: 171-178.

Schröder, T., 2005. Diapause in monogonont rotifers. Hydrobiologia 546: 291-306.

Serra, M. \& C. E. King, 1999. Optimal rates of bisexual reproduction in cyclical parthenogens with density-dependent growth. Journal of Evolutionary Biology 12: 263-271.

Sharon, M. A., A. Korzarova, J. S. Clegg, P. O. Vacratsis \& A. H. Warner, 2009. Characterization of a group 1 late embryogenesis abundant protein in encysted embryos of the brine shrimp Artemia francisacana. Biochemistry and Cellular Biology 87: 415-4310.

Snell, T. W., J. Kubanek, W. Carter, A. B. Payne, J. Kim, M. K. Hicks \& C. P. Stelzer, 2006. A protein signal triggers sexual reproduction in Brachionus plicatilis (rotifera). Marine Biology 149: 763-773.

Storey, K. B., 2003. Mammalian hibernation. Transcriptional and translational controls. Advances of Experimental Medicine and Biology 543: 21-38.

Storey, K. B. \& J. M. Storey, 2007. Tribute to P.L.Lutz: putting life on 'pause' - molecular regulation of hypometabolism. Journal of Experimental Biology 210: 1700-1714. 
Suga, K., D. Mark Welch, Y. Tanaka, Y. Sakakura \& A. Hagiwara, 2007. Analysis of expressed sequence tags of the cyclically parthenogenetic rotifer Brachionus plicatilis. PLoS One 2: e671.

Suga, K., D. Mark Welch, Y. Tanaka, Y. Sakakura \& A. Hagiwara, 2008. Two circular chromosomes of unequal copy number make up the mitochondrial genome of the rotifer Brachionus plicatilis. Molecular Biology and Evolution 25: 1129-1137.

Tunnacliffe, A. \& M. J. Wise, 2007. The continuing conundrum of LEA proteins. Naturwissenschaften 94: 791-812.

Tunnacliffe, A., J. Lapinski \& B. McGree, 2005. A putative LEA protein, but no trehalose, is present in anhydrobiotic bdelloid rotifers. Hydrobiologia 546: 315-321.

Walters, C., L. M. Hill \& L. J. Wheeler, 2005. Dying while dry: kinetics and mechanisms of deterioration in desiccated organisms. Integrative and Comparative Biology 45: 751-758.

Wang, J. \& S. K. Kim, 2003. Global analysis of dauer gene expression in Caenorhabditis elegans. Development 130: 1621-1634.

Wheelock, C. E., T. A. Baumgartner, J. W. Newman, M. F. Wolfe \& R. S. Tjeerdema, 2002. Effect of nutritional state on Hsp60 levels in the rotifer Brachionus plicatilis following toxicant exposure. Aquatic Toxicology 61: 89-93.

Wurdak, E. S., J. J. Gilbert \& R. Jagels, 1978. Fine structure of the resting eggs of the rotifers Brachionus calyciflorus and Asplanchna sieboldi. Transactions of the American Mircoscopical Society 97: 49-72. 